University of Nebraska - Lincoln

DigitalCommons@University of Nebraska - Lincoln

2013

Developing a Mathematics Capstone Experience at The U.S. Air

Force Academy

Kurt Herzinger

Trae Holcomb

Dale Peterson

Beth Schaubroeck

Follow this and additional works at: https://digitalcommons.unl.edu/usafresearch

This Article is brought to you for free and open access by the U.S. Department of Defense at

DigitalCommons@University of Nebraska - Lincoln. It has been accepted for inclusion in U.S. Air Force Research by an authorized administrator of DigitalCommons@University of Nebraska - Lincoln. 


\title{
Developing a Mathematics Capstone Experience at The U.S. Air Force Academy
}

\author{
Kurt Herzinger, Trae Holcomb, Dale Peterson, and Beth Schaubroeck
}

\begin{abstract}
There are many details to consider when designing a capstone experience. Expectations of students, faculty workload, resources, logistics, and timing all play a part in the value of this endeavor. We discuss the experience of creating a research capstone experience from scratch including the components of our current course as well as lessons learned. Supplementary materials are available for this article. Go to the publisher's online edition of PRIMUS to view the supplemental file.
\end{abstract}

Keywords: Capstone, research.

\section{INTRODUCTION}

In this paper we discuss the development over the past several years of a mathematics capstone experience at the United States Air Force Academy (USAFA). We have learned a great deal during the process, and it is our hope that others will benefit from our experience.

In 2006 we began preparations for offering a capstone experience. After many draft proposals and discussions, we conducted a trial run in the academic year 2009-2010 with two senior math major volunteers. The most important component of the experience was that each student complete a research project guided by a faculty mentor. They were also required to solve challenge problems and take a comprehensive exam covering core math major topics. After making a few small adjustments, we made the capstone a requirement for our math majors in 2010-2011.

This article not subject to US copyright law.

Address correspondence to Beth Schaubroeck, Department of Mathematical Sciences, United States Air Force Academy, USAF Academy, CO 80840, USA. E-mail: beth.schaubroeck@usafa.edu 
The creation of a capstone experience presented challenges that are distinct from those of other mathematics courses. We will discuss these challenges, how we are addressing them, and how this is resulting in an experience that allows students to develop in ways that traditional courses do not always inspire.

\section{BACKGROUND}

For many years our department required our math majors to take a senior seminar in the fall of their senior year. The course was worth 0.5 credit hours (in its last few years it was reduced to 0.0 credit hours) and was graded on a pass/fail basis that was not factored into their grade point average. Not surprisingly, students often directed their efforts toward other courses. The value of the senior seminar with respect to the development of our math majors was questionable at best.

In 2006, our department head requested the creation of a senior capstone experience in mathematics that would be a graduation requirement for the students in the class of 2011 and beyond. In subsequent years, we began forming focus groups composed of senior math majors. Their feedback supported the offering of a capstone experience. Several of the engineering majors at USAFA offer capstones, and our math majors wanted to have the same kind of culminating experience. We recruited a committee within the department to work on this enterprise. We sought guidance from other departments that had wellestablished capstone experiences and obtained information from mathematics programs outside of our institution about their capstone courses. Equipped with this information, the committee identified two goals: engage the students in significant research efforts and support our math major Educational Outcomes. These desired outcomes for our graduates are that they should:

1. Display proficiency with the topical content included in the math major curriculum.

2. Be able to effectively communicate topics related to mathematics and statistics.

3. Be able to apply principles of science and the scientific method to frame and resolve a wide variety of problems related to mathematics and statistics.

4. Engage in a lifelong learning process via the ability to self-educate.

Learning how to conduct research is an important part of Educational Outcome 4 and is essential for preparing students for their mathematical careers and graduate study (see [2]). Our students are given the opportunity to develop some research skills via various small projects in several of our upper-division courses. The committee recognized, however, that the capstone experience 
provides a prime opportunity for helping the students develop much further in this area.

\section{BUILDING THE COURSE}

Armed with the two goals that the capstone must require research and support our Educational Outcomes, we crafted a capstone experience for the two students who volunteered for our 2009-2010 trial run. We refined it based on their feedback. The resulting design (and the ideas behind it) are described in the following subsections.

\subsection{Course Structure}

To provide an authentic research experience along with sufficient opportunities for the students to develop with respect to the Educational Outcomes, we decided the capstone must be a two-semester course sequence, with each semester being worth three credit hours. Adding to the number of credit hours required for the degree was not an option. The major requires 42 credit hours (beyond the core curriculum required for all USAFA students), 15 of which were already listed as "open courses." That is, the students had the freedom to choose which courses to take to earn these hours. Typically, these were mathematics courses or courses related to the mathematical sciences that were approved by the department. To accommodate the addition of the capstone experience, the number of open course credit hours was reduced to nine.

We also had to decide how to deal with double majors who were required (or desired) to complete a capstone experience in their other discipline. Our majors can satisfy our capstone requirement by completing six capstone credit hours, whether they be in our department, their other discipline, or a combination of the two. If the other discipline has a capstone worth less than six credit hours, then arrangements are made for the student to take part in the mathematics capstone in a capacity that accounts for the reminder of the required six credit hours. For example, students double majoring in mathematics and physics can take the three-credit-hour physics capstone one of the two semesters (fall being preferred) and take three credit hours of the mathematics capstone experience. Ideally, there is coordination between the disciplines to help the two capstone experiences mesh as much as possible. A student who is not double majoring but has satisfied the prerequisites for a capstone experience in another discipline (e.g., operations research) may take that capstone instead of the mathematics capstone as long as that capstone counts for six credit hours.

The course has a single course director, a faculty member, to handle course administration and ensure course policies are applied uniformly. Students, 
under the guidance of the course director, review proposed topics and seek out a faculty mentor, as described in the next subsection.

\subsection{Mentorship and Research}

The most significant expectation for the capstone experience is that the students engage in research under the guidance of a faculty mentor. The research that the students conduct and the results they obtain do not have to be original-they must only be new to the students. The emphasis is on demonstrating the ability to conduct research. That is, the focus is on the process and not on the results themselves.

In their junior year, math majors are given information about the expectations of the capstone experience. They are encouraged to identify a mentor before the end of the spring semester so that they can hit the ground running in the fall. Prospective faculty mentors for the next year are identified and encouraged to write a description of their research to be placed on the capstone website. To avoid overloading, each faculty member mentors at most two students. (The course director may or may not be a mentor for a student in the course.) Ideally, conversations between students and faculty lead to a matching solution no later than the second week of the fall semester. In some cases, a student may wish to work with a specific faculty member because they have a well-scoped project ready to go. In other cases, the student may have an idea of their own for a project and seek a faculty member who is willing to act as a mentor. Students may engage in research in mathematics or a related field approved by the course director. The student and the faculty mentor must agree on the research topic.

The requirements associated with the student's research program, which are motivated by Educational Outcomes 2 and 4, are that each student must fulfil the following.

1. Present a research proposal to the faculty and other students. This allows the student to receive feedback on the feasibility and scope of their project.

2. Identify a published research paper that is related to the student's project and present it to the faculty and other students. This demonstrates the student's ability to read, understand, and communicate the research of others. Typically, the paper selection is carried out under the close supervision of the mentor.

3. Complete their research and write a thesis about it.

4. Present their results to the faculty and other students.

5. Present their research at a suitable math conference.

The requirement for students to present publicly is important since it develops their communication skills and is empowering in their ownership of the 
research. Moreover, the exposure to the research of others is extremely enlightening and promotes collaboration and further research. Typically, students present at a regional undergraduate meeting of the Mathematical Association of America or at the Service Academies Student Mathematics Conference, an annual conference designed to give math and operations research students from the four service academies an opportunity to present their research.

In its brief history, the capstone has already produced student research in a wide variety of subjects. The following topics have been studied in the eight capstone projects completed to date.

1. Approximating algebraic numbers using Greek ladders.

2. Analysis of adding satellites to the Global Positioning System constellation.

3. College football statistics.

4. Using partial differential equations (PDEs) in non-destructive evaluation.

5. Using PDEs in cloaking objects.

6. Mathematics and physics education.

7. Airline scheduling.

8. The mathematics behind quantum computing.

Appendix A includes the abstracts and other information about these projects. Note the diversity in the origins of the topics. They have come from, for example, Air Force assignments, conference talks, and individual faculty research interests.

\subsection{Additional Course Requirements and Schedule}

While research is the most significant component of the capstone experience, we have deliberately structured the program to enhance the student's development with respect to all of the Educational Outcomes. Therefore, the students are also required to perform the following tasks.

1. Participate in a series of lessons focused on solving challenging math problems designed to help prepare them for the Putnam competition. Students engage in the problem-solving process and present their solutions to each other. They are encouraged, but not required, to participate in the Putnam competition. This requirement supports Educational Outcomes 2 and 3.

2. Complete a take-home exam covering a broad range of topics from courses they have taken as part of the math major curriculum. While oral exams have often worked well in upper-level classes at USAFA, an oral exam did not fit well in this setting because of the volume of material that we are asking the students to synthesize. The problems involve topics from calculus through more advanced courses such as linear algebra and real analysis and are written and graded by various members of the faculty. Students are given 
2 weeks to submit solutions to eight problems, and feedback is given to the students on how they performed on each problem. This requirement supports Educational Outcome 1.

3. Write a reflective essay at the end of the capstone experience. In this essay, the students discuss how their research program went, what they learned, and how they developed with respect to the Educational Outcomes. This process of reflection is an important and valuable learning experience in its own right, and it supports Educational Outcome 4. As part of this process, the students are encouraged to provide feedback for the next offering of the capstone experience.

Choosing the building blocks for the course was fairly straightforward given our goals, but choosing how to sequence them properly across a two-semester experience was not obvious. Based on our experience running the course over the last two years, we developed the schedule shown in Appendix B.

\subsection{Grading Criteria}

USAFA policy requires that capstone courses assess student performance using letter grades instead of a pass/fail grading system. Within the department, there has been a movement over the last several years to adopt a holistic "points free" grading system in many of our upper-level major's courses as a way to improve feedback and spur student development. While not necessary, we have chosen to use such a system for the capstone experience. For information on our experiences with points-free courses, the interested reader should see [1]. Because the primary component of the capstone experience is focused on developing research skills, student performance in this area accounts for about two thirds of the overall grade. A key component of a points-free system is giving students the opportunity to self-assess their performance with respect to the outcomes and to provide input on what their mid-term and semester grades should be. The final decision on grades is based upon a conversation between the course director and the faculty mentor. Following this conversation, the mentor provides valuable feedback to the student.

\section{LESSONS LEARNED}

The first two years of the capstone have reaffirmed that there is no teacher like experience. We are incorporating the following lessons learned into upcoming offerings. Some of these lessons are based upon faculty observations and some are suggestions that came from our students. 
Get students started early. Inspire students to think about research as early as their sophomore year by encouraging them to attend undergraduate math conferences. Invite them to capstone activities such as the problem-solving lessons and student presentations. This will allow them to observe what they will be doing when they are enrolled in the capstone experience themselves. Encourage students and faculty to engage together in independent study that may arise from their mathematics courses. Advertise research topics and faculty mentors in the fall of the students' junior year, and encourage them to decide on topics and mentors before the end of the following spring semester. Facilitate student involvement in summer research, where possible. At USAFA we have a formal 6-week program called the Cadet Summer Research Program (CSRP). One of our CSRP students chose to continue his summer project for his capstone research.

Involve faculty. Advertise faculty research interests and active lines of research. Encourage faculty, particularly those who have industrial or government experience, to identify appropriate undergraduate topics that stem from their work and to consider volunteering to be a capstone mentor. Faculty who have had a recent sabbatical can be particularly helpful in this regard.

Make expectations clear. The expectations with respect to all components of the capstone experience need to be clearly communicated to both the faculty mentors and students. Each student must also clearly understand the mentor's expectations regarding the student's research efforts. Nothing detracts from the perceived value of the experience like unclear expectations. Past capstone theses should be available to new capstone students as examples of good work.

\section{BENEFITS}

The most important benefit of our capstone experience to our majors is their exposure to research and the empowerment that provides. They are required to carry out considerable independent work, which helps prepare them not only for graduate studies but also for a fruitful career regardless of occupation. Moreover, they observe the research of others, which broadens their mathematical horizons.

In some cases, project results have been delivered to industrial or government entities for their use. Such collaborations are healthy for academia and industry alike, and increase opportunities for future collaboration. Studentfaculty collaboration is also healthy for the faculty. Projects by particularly gifted students are leading to further faculty research.

The research our students have carried out may be making them more attractive to graduate schools. After the first year of our capstone experience (beyond the trial year), we observed a marked increase in the percentage of students admitted to graduate programs with six of eight students pursuing graduate work. The capstone research these students performed may have contributed to this outcome. 
Finally, the other components of the capstone experience force the students to revisit, and therefore better retain, the material they learned in their mathematics courses. It also helps them to see the connections between the content of the various courses. Based on the students' performances, we can identify strengths and correct weaknesses in our program. We are in the process of reviewing our math major program with the assistance of faculty members involved in the capstone experience.

\section{DRAWBACKS AND CHALLENGES}

Two drawbacks to the capstone experience are that it decreases the number of additional course options available to the students, and it considerably increases faculty mentor workload. We strongly believe, however, that the benefits to students and faculty described above greatly outweigh these factors.

The next two offerings of our capstone experience present some challenges that will require special attention. First, the class of 2012 has a large number of double majors that will need to combine the capstone experiences of their two disciplines. We have four physics/math double majors and one chemistry/math double major. Both physics and chemistry have a three-credit-hour capstone experience, so these students will need to also take three credit hours of the mathematics capstone. Fortunately, we identified these students early and began coordinating activities with the other departments. The plan is for all five students to enroll in the capstone experiences of the other departments for the fall semester and then enroll in the mathematics capstone in the spring. These students will miss the problem-solving section of the fall semester but will be able to participate in the take-home exam. It is our hope that cooperation between departments will enable these students to complete a research project that involves both mathematics and their other major discipline.

The second challenge is that the class of 2013 has an unusually large number of math majors, with almost twice as many as the average from the previous four years. We anticipate at least 15 students will be enrolled in the capstone experience for the 2012-2013 academic year, whereas the enrollments for the previous two years were six and nine, respectively. This will require a large number of faculty members to volunteer for duty as research mentors. Scheduling lessons for student presentations will also prove difficult with only 40 lessons in a semester. It will likely require that we run the capstone as a two-section course to allow enough presentation time in class.

\section{CONCLUSIONS}

We have discussed the establishment, administration, challenges, and advantages of implementing a mathematics capstone experience at USAFA. The 
most important element, in our view, is the research project. Other aspects of the course, such as preparing for the Putnam competition and taking a comprehensive take-home exam that covers the core math major topics, contribute to the students' development with respect to our Educational Outcomes and increases their mathematical maturity. Involving both students and faculty as much and as early as possible benefits both groups and contributes to the success of the course.

The capstone has become a key component in our major's program. We will continue to learn from experience and improve this very important developmental opportunity for our majors. It is our hope that our experiences will assist others in engaging in a similar endeavor.

\section{REFERENCES}

1. Brilleslyper, M., M. Ghrist, T. Holcomb, B. Schaubroeck, B. Warner, and S. Williams. What's the point? The benefits of grading without points. PRIMUS. 22(5): 411-427.

2. Undergraduate Programs and Courses in the Mathematical Sciences. 2004. CUPM curriculum guide. http://www.maa.org/cupm/curr_guide. html. Accessed 20 November 2011.

\section{BIOGRAPHICAL SKETCHES}

Kurt Herzinger received his education at the University of Nebraska-Lincoln, earning his Ph.D. in mathematics in 1996. He does research in problems involving numerical semigroups and seeks to engage students in research as much as possible. He enjoys cooking and believes that a pan of lasagna and a good proof are equally beautiful when both are well constructed.

Trae Holcomb studied mathematics at Texas A\&M University and the University of Colorado at Colorado Springs. He likes teaching a wide variety of undergraduate mathematics courses and does research related to numerical semigroups. He enjoys engaging in family activities, playing speed chess, and learning Spanish.

Dale Peterson's career includes 10 years in the space systems industry, including projects such as the Strategic Defense Initiative and the Global Positioning System.

Beth Schaubroeck studied complex analysis at the University of North Carolina. She enjoys teaching at all levels of the undergraduate curriculum and especially enjoys working with new faculty members in the department. She tries to spend as much time as possible watching her husband and sons play softball and baseball. 